\title{
Accuracy assessment for Landsat 8 thermal bands in measuring sea surface temperature over Kuwait and North West Arabian Gulf
}

\author{
Jasem A Albanai ${ }^{1,2^{*}}$, Sara A Abdelfatah ${ }^{3}$ \\ ${ }^{1}$ Marine Monitoring Section, Water Quality Monitoring Department, \\ Environmental PublicAuthority, Kuwait \\ ${ }^{2}$ Chairman's office, Public Authority for Agriculture Affairs and Fish Resources \\ (PAAF),Kuwait \\ ${ }^{3}$ Dept. of Geography, College of Graduate Studies at Kuwait University, Kuwait \\ * Corresponding author: albanay.com@gmail.com
}

\begin{abstract}
Studying physical oceanography is one of the important fields of remote sensing applications. Previously, the thermal mapping of seas and oceans relied on primitive methods, such as the use of sensors installed on buoys, extracting contour lines, and deriving the values from the confluence of contour lines. Today's remote sensing provides more advanced methods for extracting sea surface temperature (SST) values for all bodies of water as a continuous raster model, through thermal sensors installed on satellites designated to monitor and observe the Earth. The Landsat program has facilitated a quantum leap by providing its data free for the public. What has become increasingly important is the inclusion, in Landsat 8 , of a thermal band on the TIRS sensor through which SST can be extracted with a spatial resolution of 100 $\mathrm{m}^{2}$. In this article, the accuracy of the two thermal bands (band 10 and 11) of Landsat 8 was validated in estimating the SST of Kuwaiti and Northwest Arabian Gulf waters, through the use of 62 thermal images and 66 ground-truthing points (GTPs) taken from the field in the period from July 2013 to March 2020. This was achieved through a function provided by the ENVI 5.3 software - "brightness temperature" - to derive the surface temperature. The accuracy of Landsat 8 to monitor the SST of Kuwait and north-west Arabian Gulf waters was validated by calculating the root mean square error (RMSE) and the mean absolute percentage error (MAPE). The accuracy of the thermal band 10 was \pm 2.03 degrees $(7.9 \%)$, while the accuracy of the thermal band 11 was \pm 3.13 degrees $(13.7 \%)$. Therefore, this study demonstrated that the thermal band 10 of Landsat 8 is more accurate than the thermal band 11 in monitoring the SST of Kuwaiti and north-west Arabian Gulf waters, with a difference of \pm 1.1 degrees $(5.8 \%)$.
\end{abstract}

Keywords: Arabian Gulf; Kuwait; physical oceanography; remote sensing; sea surface temperature (SST).

\section{Introduction}

SST is an important variable that affects the physical properties of water. Seawater temperature affects the biodiversity of marine life, as well as it is a good indicator of water quality (Wloczyk et al., 2006). A slight increase or decrease in the seawater temperature can cause environmental impacts such as a change in the distribution of marine organisms. Besides, long-term SST measurements are useful in climate studies (Ahn et al., 2006).

Previously, such studies relied on primitive methods in the thermal mapping of seas and oceans, such as using measurements from sensors installed on floating marine stations (buoys) and extracting contour lines, and deriving the values from the confluence of 
these lines. Measuring SST from space using earth observation satellites is a technique that has been applied since the 1980s (Syariz et al., 2015). The Advanced Very High-Resolution Radiometric (AVHRR) satellite, with its five thermal channels with a spatial resolution of $1.1 \mathrm{~km}^{2}$, is the most used satellite for measuring SST (Al-Rashidi et al., 2009). In the past, low spatial resolution was one of the obstacles to accurately measure the SST. Therefore, accurate algorithms have since been developed to generate more accurate SST values (Wloczyk et al., 2006).

Landsat 8 is one of the satellites with available data for free. The launch of Landsat 8 was a huge step in the field of thermal imaging, as it was equipped with a Thermal Infrared Sensor (TIRS) with a spatial resolution of $100 \mathrm{~m}^{2}$. The TIRS has two bands: the thermal infrared band 10 covers the radiation ranges from 10.60 to $11.19 \mu \mathrm{m}$, while the radiation of the thermal infrared band 11 ranges from 11.50 to $12.51 \mu \mathrm{m}$. The temporal resolution of Landsat 8 is 16 days which means that every specific geographical region should be captured every 16 days by the satellite (USGS, 2020b). Landsat 8 data have been widely used to extract surface temperature data for both land and water. Surface temperature is extracted from Landsat 8 imagery by converting digital numbers, a primary formula by which satellite images are preserved into radiance. Then, the equation for the extraction of temperature is applied either in Kelvin or in Silesian. Recently, some software, such as ENVI 5.3 has provided a function (brightness temperature) to extract surface temperature directly (L3HARRIS, 2020). The accuracy of this equation (function) differs spatially, as it is more accurate in some geographical regions than others, depending on certain physical and environmental conditions. As a result, the accuracy of thermal models extracted from satellites is measured by appropriate statistical measures. However, regression analysis is widely used to adjust satellite pixel values based on ground trothing points and field measurements.

Several studies have already discussed SST in the North Arabian Gulf region. Some rely on AVHRR thermal data with a spatial resolution of $4 \mathrm{~km}^{2}$ (Al-Rashidi et al., 2009). Others use MODIS products with a spatial resolution of $1 \mathrm{~km}^{2}$ (Moradi \& Kabiri, 2015; Barseem et al., 2014; Ghanea et al., 2016). Several studies are based on field measurements in mapping SST over the region (Alyamani et al., 2004). This study aims to evaluate the accuracy of Landsat 8 thermal bands' "brightness temperature equation" in estimating SST using field data taken from 2013 to 2020 in Kuwait territorial waters.

\section{Study area}

The State of Kuwait is located in the northeast of the Arabian Peninsula approximately between $28.45^{\circ}$ and $30.05^{\circ}$ North latitude and $46.30^{\circ}$ and $48.30^{\circ}$ East longitude, with an area of 17,818 $\mathrm{km}^{2}$ (Figure 1). Kuwait has a sub-tropical climate, with long dry summers and short winters, and a lack of rainfall. The prevailing wind comes from the northwest, and blows most days of the year (Albanai, 2019). The population is concentrated in the urban area and is distributed across six provinces, Asimah, Hawali, Al-Farwania, Jahra, Mubarak Al-Kabeer, and Ahmadi. The total population of 2018 was estimated to be 4,768,754, including Kuwaitis and NonKuwaitis (PACI, 2018). 


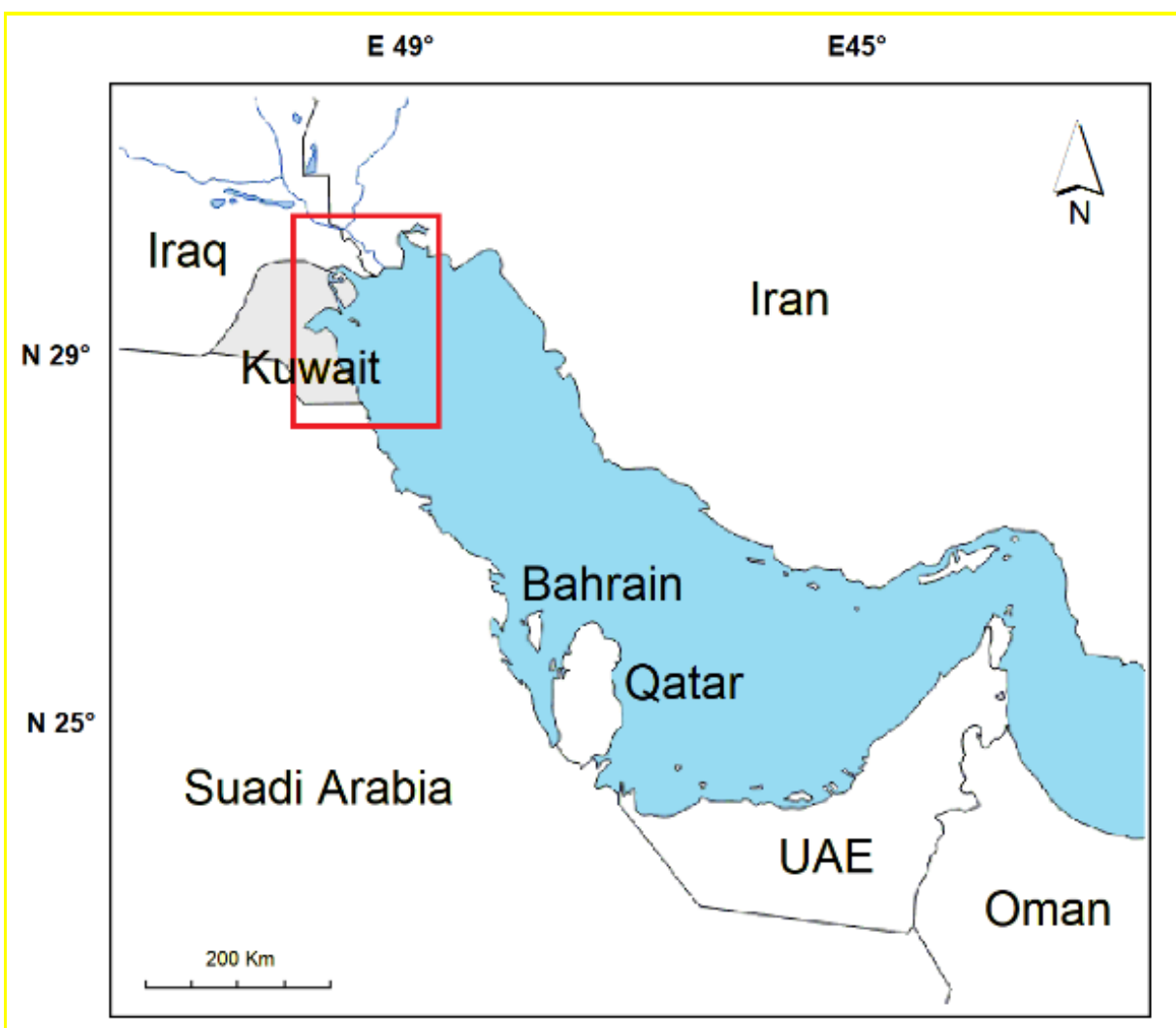

Fig. 1. Study area, which located on the northeast of the Arabian Gulf.

Kuwait faces the Arabian Gulf, and its coastline stretches to more than $1000 \mathrm{~km}$, including the coasts of the islands and the new artificial beaches and reclamation. The nature of the coasts varies from north to south, depending on the location and the type of sediment. The sand and mud beaches prevail in the northern region, while the southern region is characterized by its sandy beaches (Taylor et al., 2015). There are nine islands in Kuwaiti waters, which can be divided according to their physiography into two groups. The first group is coastal islands in the northern waters, and they include Warba, Bubyan, Miskan, Failaka, Awhah, and Umm AlNamil. The second group is located off Kuwait's shore in the southern part of the territory, where the water is deeper. They are Umm Al-Maradim, Qaruh, and Kubbar (Alyamani et al., 2004).

The depth of the Kuwait seawater in the north is different from that in the south, where the water is shallow in the north due to the accumulated mud deposits while deep in the south; even here, the general depth of the seawater does not exceed 30 meters. The salinity of Kuwaiti seawater fluctuates with a mean of 42.4 practical salinity units (PSU). Generally, salinities in the north of Kuwait are lower than in the south, due to the Shatt Al-Arab discharge. Also, the temperature of Kuwait seawater varies from north to south, where the temperature of northern waters is colder than southern and offshore waters. The seawater temperature ranges from 35 $\mathrm{C}^{\circ}$ in summer to $12.5 \mathrm{C}^{\circ}$ in winter, with an annual average of $24.8 \mathrm{C}^{\circ}$. Based on existing records, the highest average temperatures were measured in July and August and the lowest average temperatures were measured in January and February. In general, Kuwait's waters have low clarity and transparency because of the shallowness, with mean turbidity of 13.5 
nephelometric turbidity units (NTU); the highest values occur at Bubyan creeks. The chlorophyll- $a$ average is about 2.12 on Kuwait territorial waters. The seawater temperature of Kuwait is measured mostly through floating monitoring stations of the competent authorities, although these are occasionally supplemented by field surveys conducted by these authorities (Albanai, 2021a and b).

\section{Methodology}

\subsection{Data description and fieldwork}

Ground truthing points (GTPs $n=66$ ) of Kuwaiti SST cover eight years, from July 2013 to March 2020, and are collected from two sources: the field survey with the Environmental Public Authority's (Environmental Public Authority, 2020) instruments for monitoring SST from 2018 to 2020; and the Meteorological Department in Kuwait Airways (Kuwait Meteorological Department, 2020), which provided us with the SST values from 2013 to 2017. All the field data were measured at around 10:00 am, while Landsat 8 captured images in the period from 9:30 to 10:30 am in local time. All the stations were along Kuwait's territorial waters, from Kuwait Bay to the southern territory.

The spatial data in this study include raster and vector layers. The raster layers contain satellite images archives from Landsat 8 (Figure 2), which provided us with images from July 2013 to March 2020. The Landsat level-1 images $(n=62)$ were freely downloaded from the Survey United States Geological Survey's (USGS) website (USGS, 2020a). The vector layers contain two sub-layers: the marine station's points layer, of the Environmental Public Authority (Environmental Public Authority, 2020), and the station's points layer of the Meteorological Department in Kuwait (Kuwait Meteorological Department, 2020). Both vector layers have been made by the authors, using the two organizations' station coordinates.

\subsection{Data pre-processing}

The 62 Landsat 8 images were pre-processed using ENVI 3.5 software. The images have subsets, both spatially and spectrally. Landsat 8 image has eleven bands, two of which are the thermal bands of the TIRS sensor. One plate of the Landsat 8 image covers a wide area including the land and sea; the objective in this study is the body of Kuwait's seawater (in the north-west Arabian Gulf). Following that, the two thermal bands of Landsat 8 were processed by converting the digital numbers (a primary format in which data are stored) into brightness temperature, an option provided by the ENVI 5.3 software as a function under radiometric calibration tools to extract the surface temperature of the land, "including water". This function is computing using the following formula (L3HARRIS, 2020):

$$
T=\frac{K 2}{\ln \left(\frac{K 1}{L_{\lambda}}+1\right)}
$$

(Equation 1) 
Where $K 1$ and $K 2$ are calibration constants in Kelvin. ENVI 5.3 software reads these values from the Landsat metadata. $L_{\lambda}$ is the Radiance in $\mathrm{W} /\left(\mathrm{m}^{2} *\right.$ steradian $\left.* \mu \mathrm{m}\right)$ units. $T$ is the derived surface temperature.

The thermal images (two thermal bands for each image) were calculated in Kelvin and were converted to degrees Celsius using the band math tool in the software. In the end, the images were converted from ENVI format to a TIF format which can be used in ArcGIS software for matching purposes.

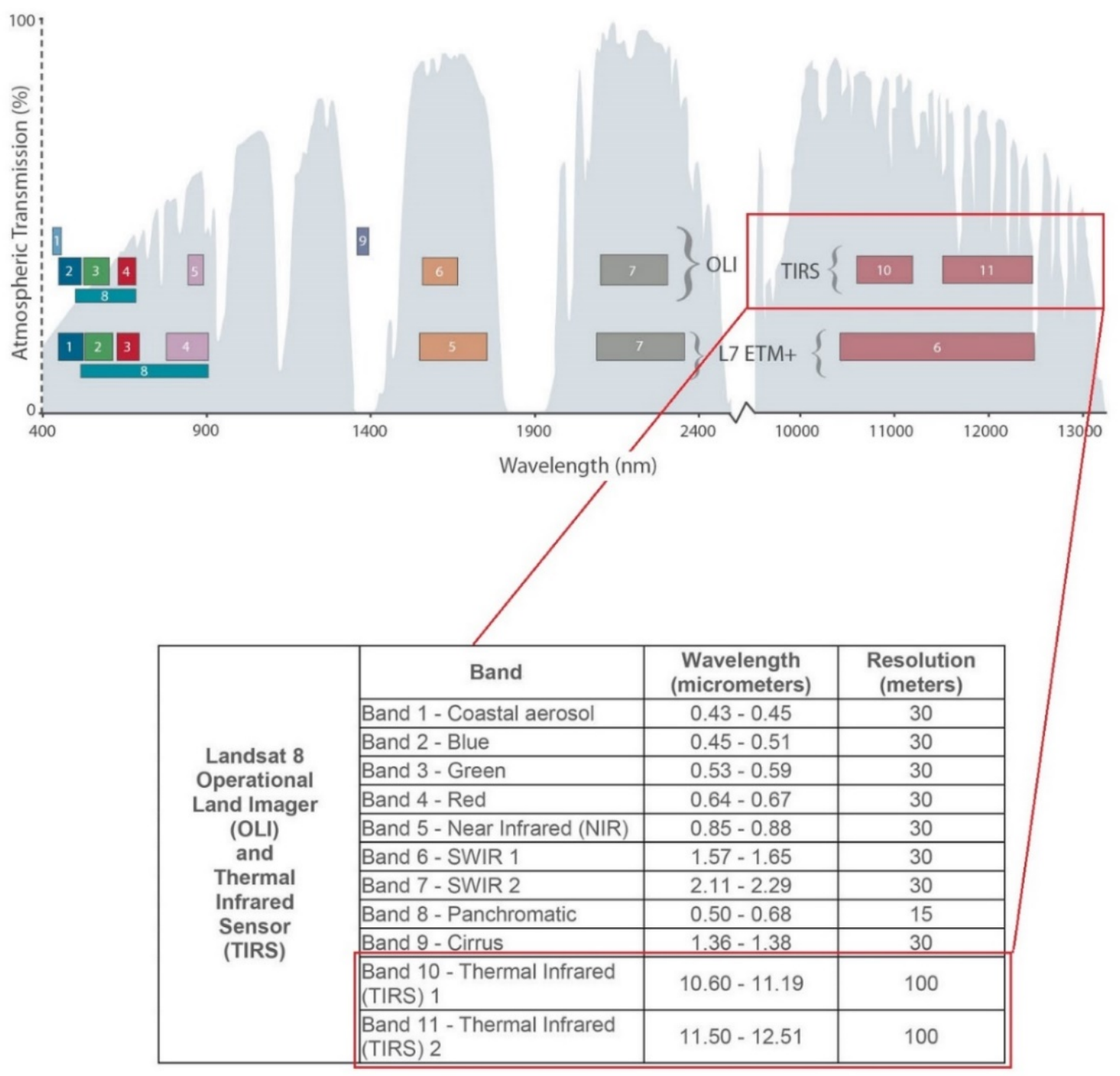

Fig. 2. Landsat 8 spectral bands with their spatial resolution and their range in the atmospheric transmission (NASA, 2020; USGS, 2020b).

\subsection{Geospatial analysis}

For matching between the ground-truthing points and the two thermal bands of Landsat 8, a buffer was created around each ground-truthing point covering $1 \mathrm{~km}^{2}$ of Landsat 8 thermal 
image. Then, the average values and standard deviations of these pixels were extracted, to extract the coefficient of variance (CV) (Figure 3). This technique has been applied by numerous studies (Albanai, 2020; Albanai, 2021c). This indicator has been extracted for detecting outliers' values, as they may be present in the image as a result of high and low reflection due to weather conditions, or the presence of any malfunctions, or even any pollution or foreign object in the water. A value of greater than one is specified as an overhead, and images exceeding this value are excluded from the analysis. All the previous steps were done using the Arc toolbox in ArcGIS 10.4.1.

The following formula was used to compute the coefficient of variance (CV):

$$
C V=\left(\frac{S}{\bar{x}}\right) 100
$$

\section{(Equation 2)}

Where $S$ is the standard deviation and $\bar{x}$ is the mean value in pixels window of Landsat 8 thermal bands.

This was followed by a comparison of the values extracted from the two thermal bands for each image and the ground-truthing points, by calculating the root mean square error and the mean absolute percentage error. These are all statistical indicators that show the rate of difference between the two variables in the unit of measurement used. In this analysis, the RMSE scores were in degrees, and the MAPE was in percent. The following formulas were used to compute RMSE and MAPE respectively:

$$
R M S E= \pm \sqrt{\frac{1}{n} \sum_{i=1}\left(f_{i}-f_{j}\right)^{2}}
$$

(Equation 3)

$$
M A P E=\frac{1}{n} \sum_{i=1}\left|\frac{f_{i}-f_{j}}{f_{i}}\right| 100
$$

(Equation 4)

Where $f_{i}$ is the value of ground-truthing point and $\mathrm{fj}$ is Landsat 8 thermal bands mean value in pixels window. Figure 4 . Shows the methodology summary 

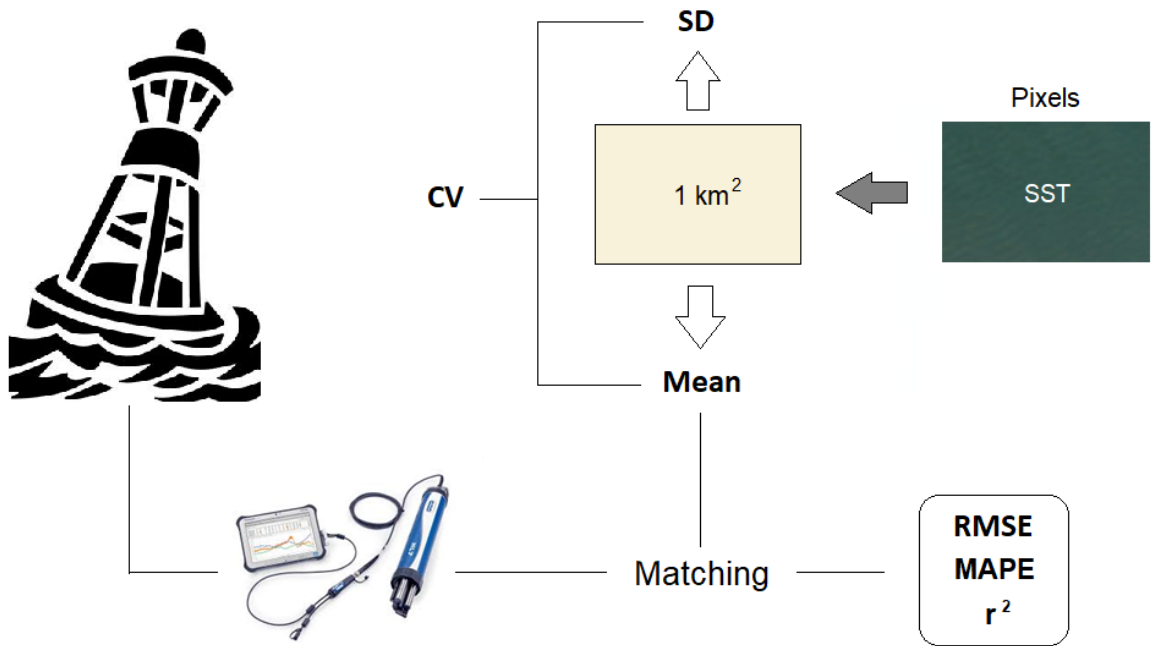

Fig. 3. Matching summary. As for the in-situ data, SST data were measured by taking the mean of 10 minutes' measure in the specific time and location.

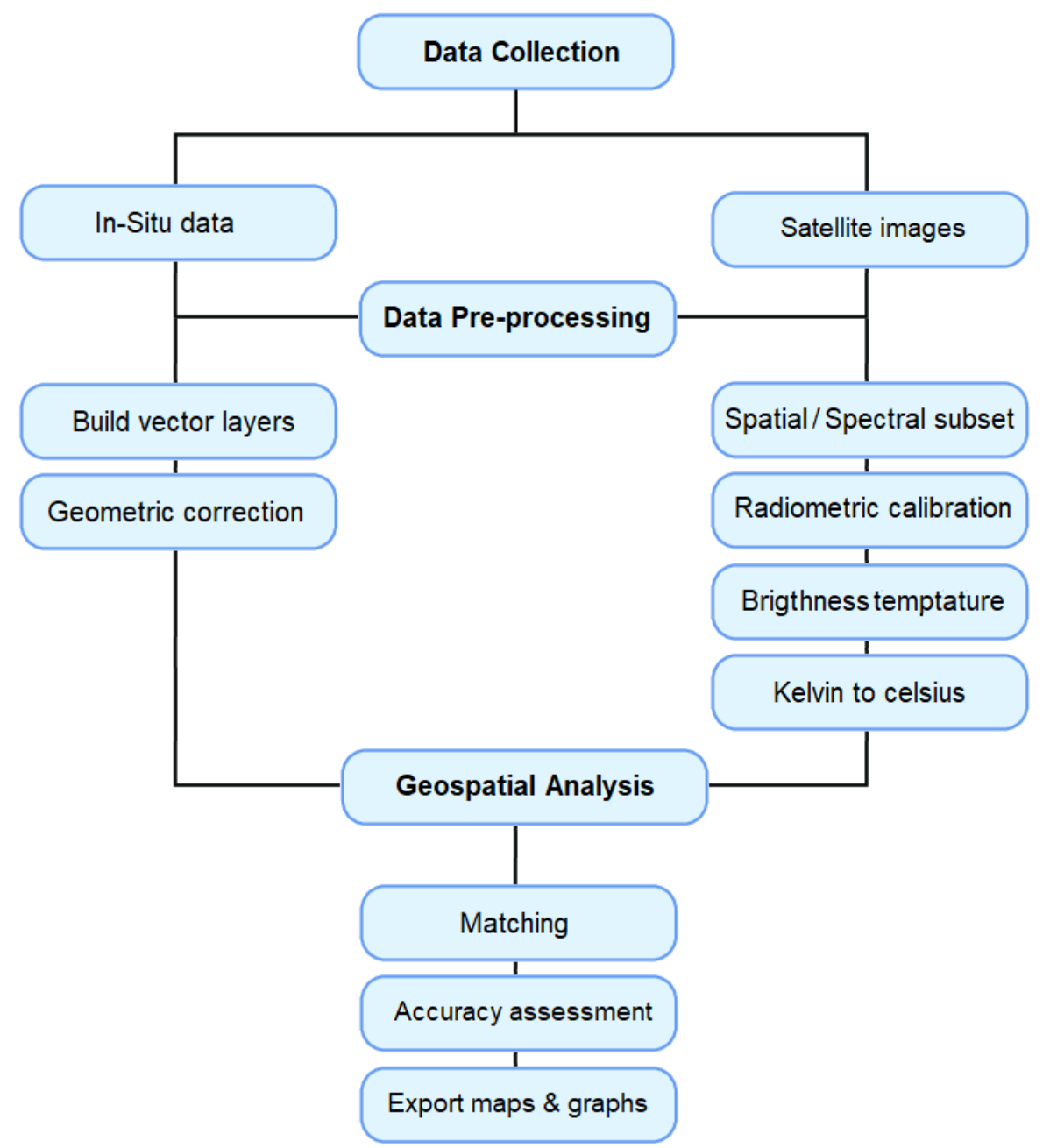

Fig. 4. Methodological flow chart for the current study. 


\section{Results and discussion}

The accuracy provided by the "brightness temperature" function of the ENVI 5.3 software in extracting SST of Kuwaiti seawater across the two thermal bands of Landsat 8 was evaluated, using 66 ground-truthing points taken from field survey and floating marine buoys with 62 thermal images (Figures 5 and 6). It was found, according to statistical measures such as the RMSE and MAPE, that thermal band 10 of Landsat 8 is better in monitoring SST than thermal band 11 (Table 1) in Kuwait and the Northwest Arabian Gulf with a difference of \pm 1.1 , where the accuracy of the thermal band 10 was \pm 2.03 (7.9\%), while the accuracy of the thermal band 11 was $\pm 3.13(13.7 \%)$. The raster model of the thermal bands of Landsat 8 showed homogeneity, with CV (Table 2) not exceeding one degree in any thermal image overall the seasons (Figures 7 and 8). Some studies (Ghanea et al., 2016) show a proportional relation for other sensors such as MODIS in SST monitoring in the northern Arabian Gulf with field data $\left(\boldsymbol{r}^{2}=0.989\right)$, which confirms that building a new empirical model will enhance the accuracy of the Landsat 8 SST estimating. Figure 9 shows the geographical distribution of the SST in the waters of Kuwait and the North West Arabian Gulf through two images captured in the summer and winter. The images show the spatial resolution of the thermal bands of Landsat 8 .

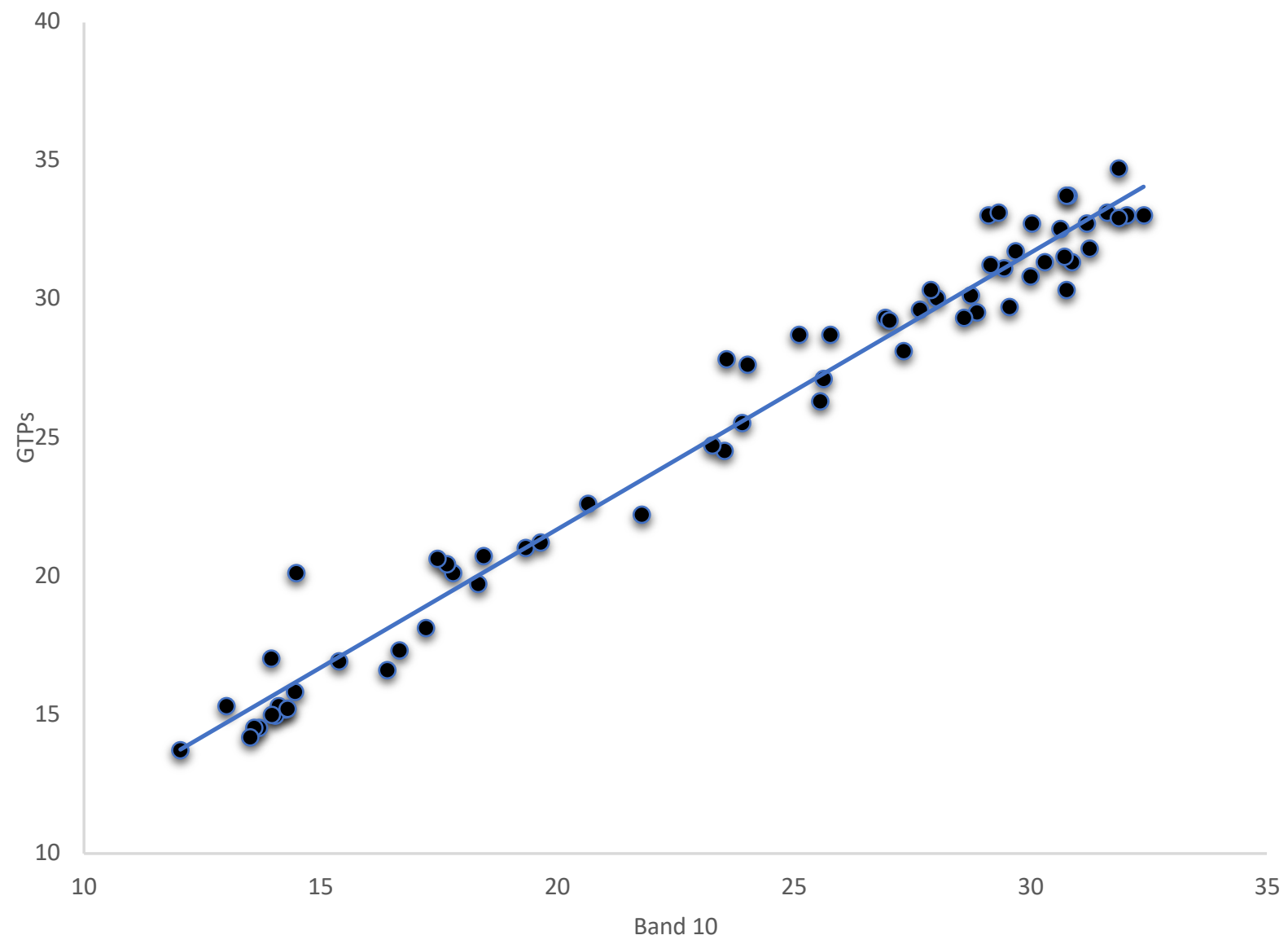

Fig. 5. The correlation between thermal infrared band 10 and GTPs. 


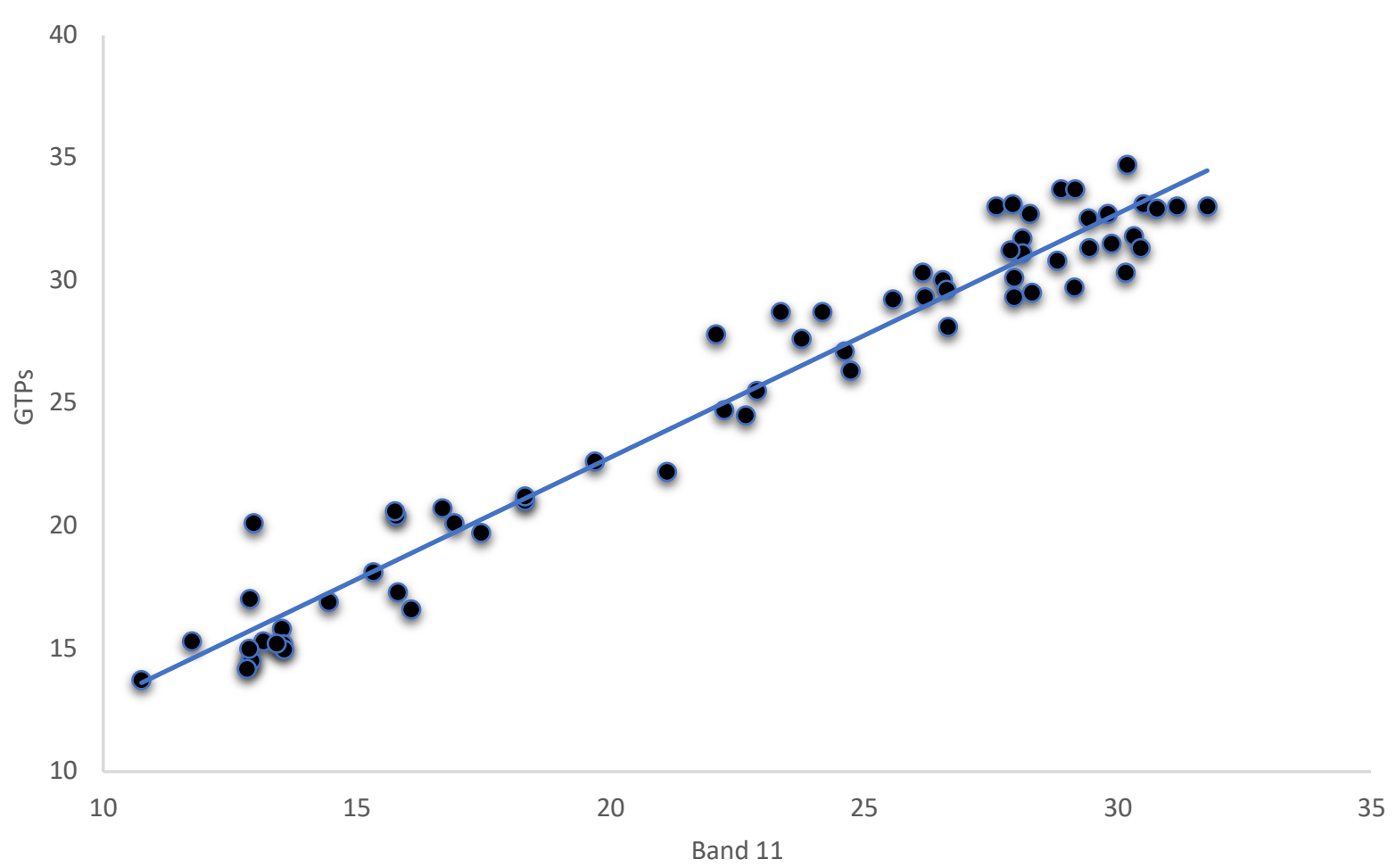

Fig. 6. The correlation between thermal infrared band 11 and GTPs.

Table. 1. RMSE, MAPE and $r^{2}(\mathrm{p}$-value $=.000)$ scores.

\begin{tabular}{lccc}
\hline & RMSE $\left(\mathbf{C}^{\circ}\right)$ & MAPE $\left(\mathbf{C}^{\circ}\right)$ & $\boldsymbol{r}^{\mathbf{2}}$ \\
\hline Thermal band 10 & 2.03 & 2.66 & 0.97 \\
Thermal band 11 & 3.13 & 3.4 & 0.96 \\
\hline
\end{tabular}

Table. 2. Mean standard deviation and mean CV scores seasonally and over the years concluded in the study.

\begin{tabular}{cccc}
\hline & Season & Mean SD & Mean CV \\
\hline \multirow{3}{*}{ Thermal band 10 } & Winter & 0.08 & 0.22 \\
& Spring & 0.0322 & 0.2 \\
& Summer & 0.0324 & 0.11 \\
& Fall & 0.03 & 0.12 \\
\hline & Year & $\mathbf{0 . 0 3}$ & $\mathbf{0 . 1 5}$ \\
\hline \multirow{3}{*}{ Thermal band 11 } & Winter & 0.03 & 0.29 \\
& Spring & 0.032 & 0.18 \\
& Summer & 0.023 & 0.1 \\
& Fall & 0.026 & 0.11 \\
\hline & Year & $\mathbf{0 . 0 2}$ & $\mathbf{0 . 1 5}$ \\
\hline
\end{tabular}




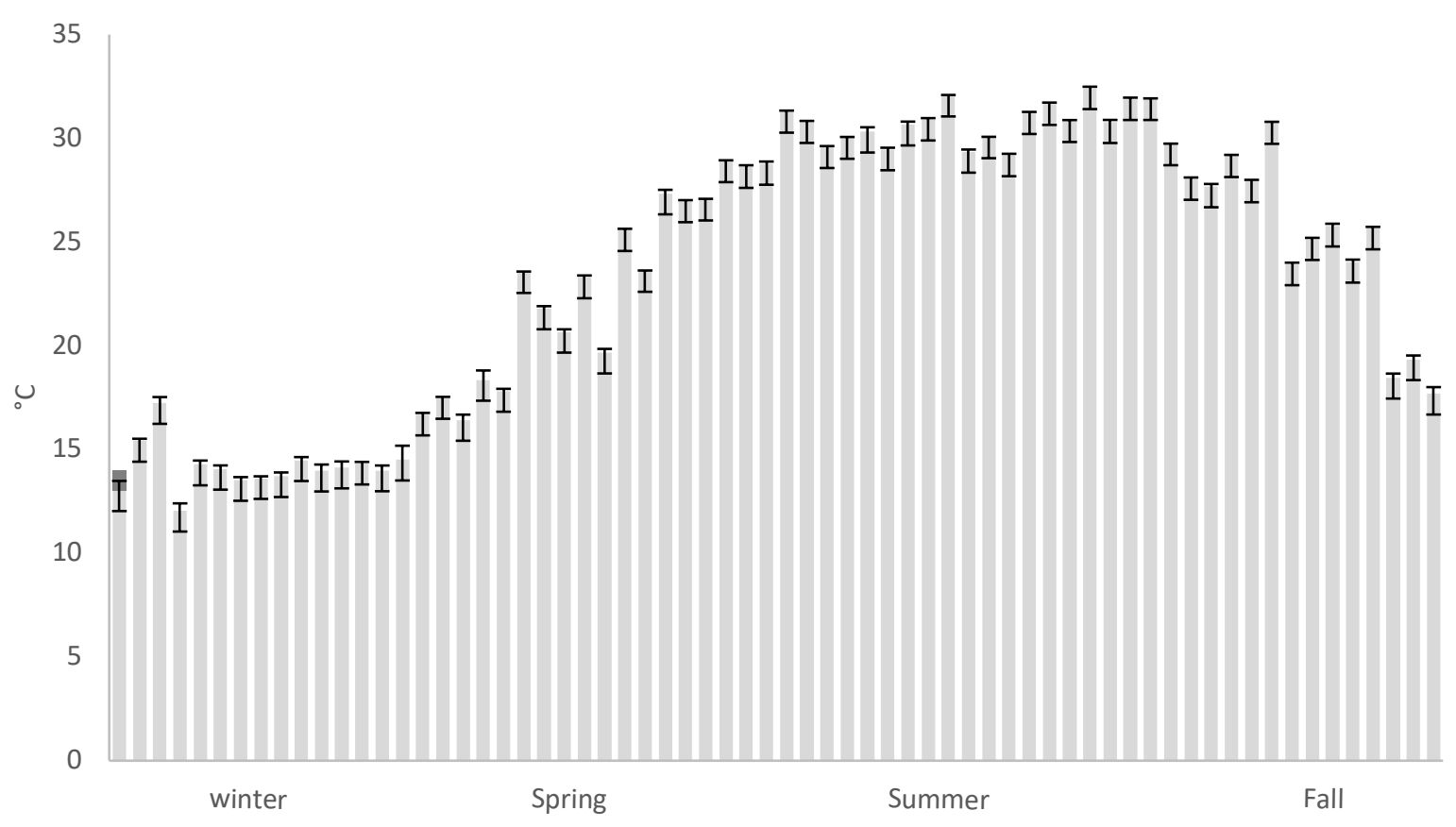

Fig. 7. Mean values (error bars represent CV values) for the thermal infrared band 10 images.

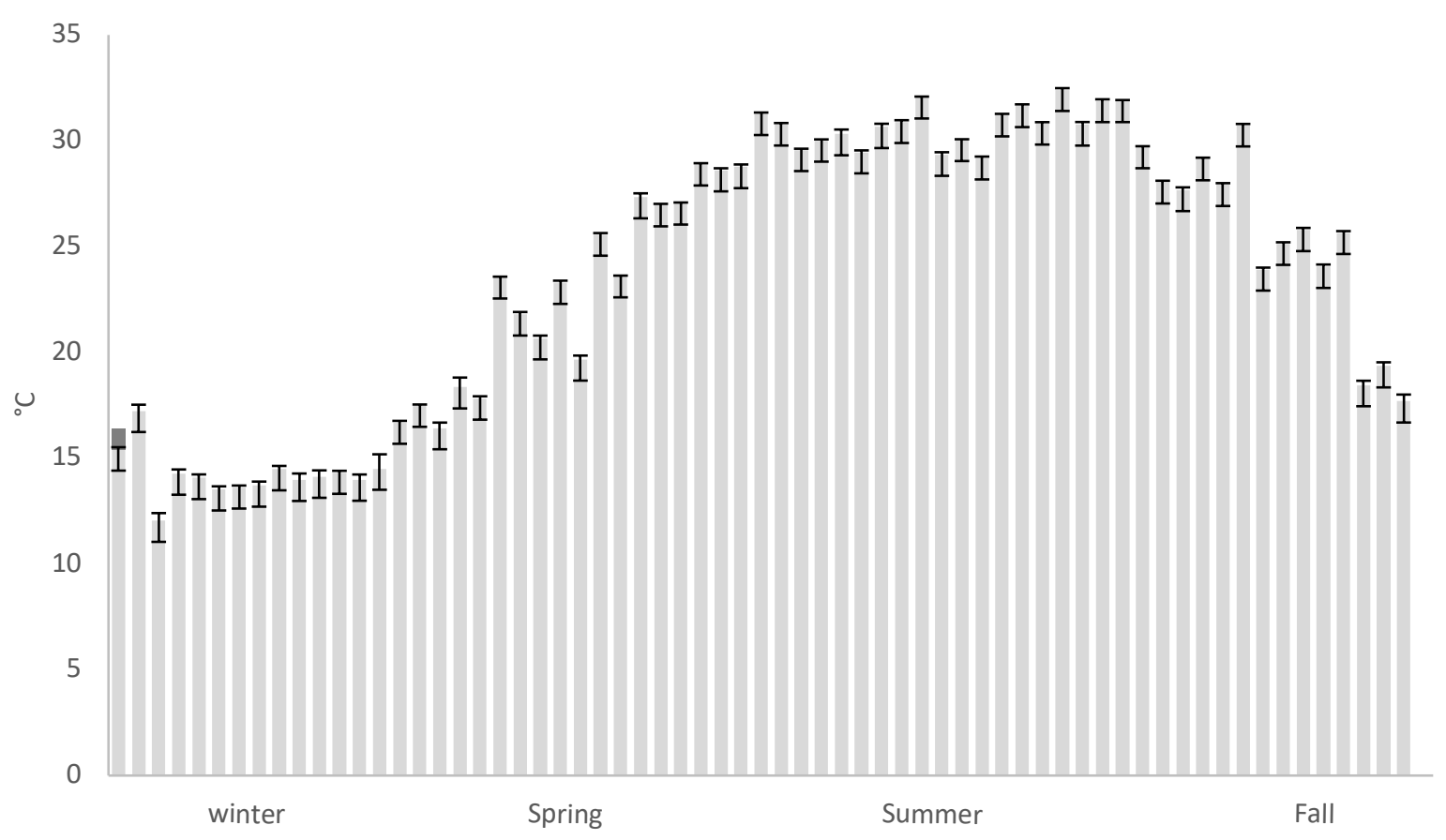

Fig. 8. Mean values (error bars represent CV values) for the thermal infrared band 11 images. 

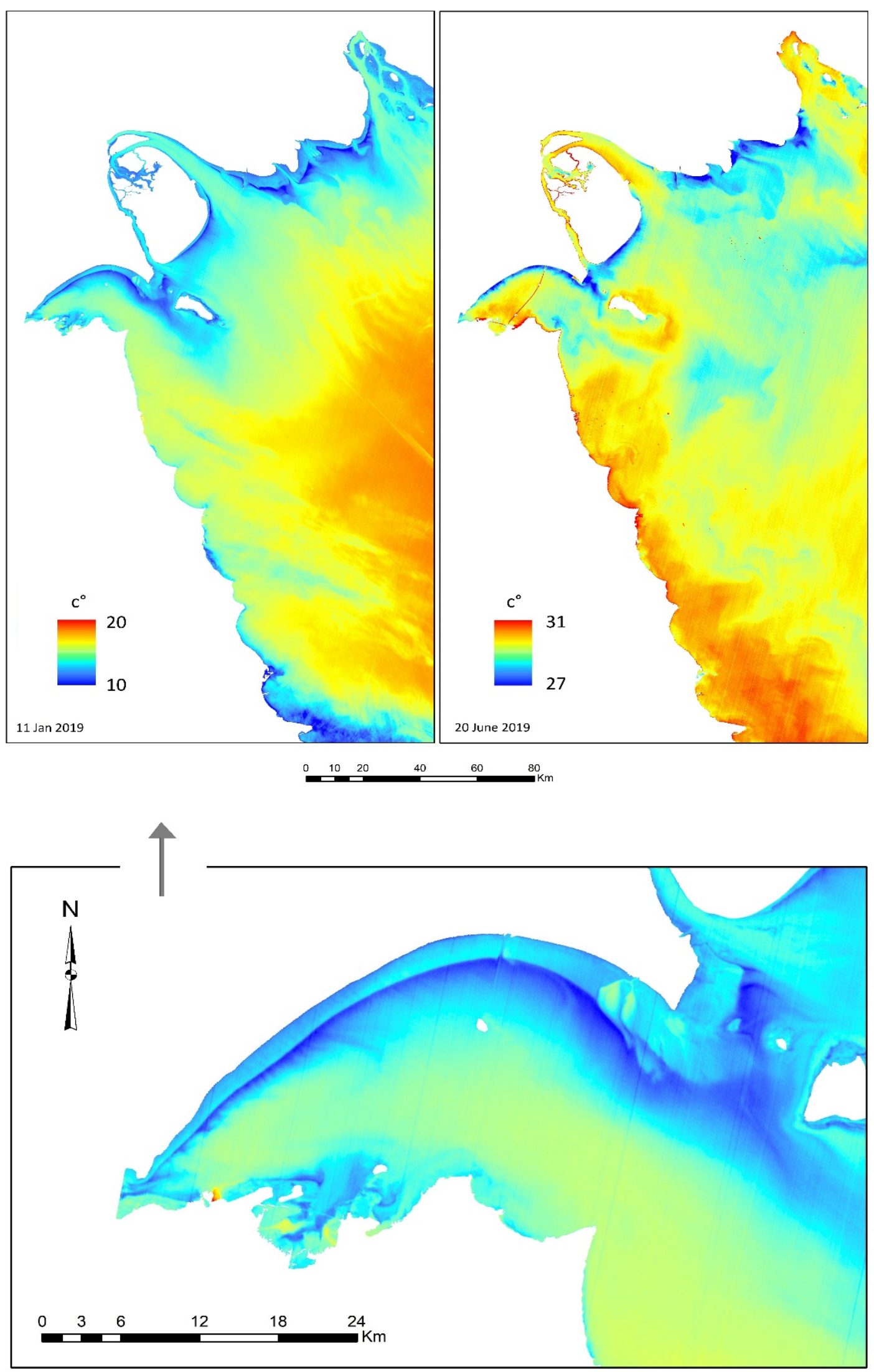

Fig. 9. An example of the obtained sea surface temperature values across Kuwait and the Northwest Arabian Gulf using Landsat 8 Thermal band 10. The map below shows the spatial resolution of the obtained model in Kuwait Bay. 


\section{Conclusion}

In this article, the accuracy of Landsat 8 thermal bands was evaluated by GTPs from 2013 to 2020. Based on the results, it is recommended to use thermal band 10 of Landsat 8 to monitor SST in Kuwait and the Northwest Arabian Gulf when using brightness temperature function. Although the study relies on quantitative analysis, relying on GTPs with a spread geographic distribution more than what is applied in this study will give more accurate results in monitoring accuracy. Further studies and research are recommended to derive a new model with better accuracy in monitoring SST in this geographical region. In general, ENVI 5.3's brightness temperature function showed a good ability to monitor SST and clarify the spatial distribution in the study area, though there is a possible opportunity to improve accuracy through the use of remote sensing methods and geographic information systems (GIS) solutions.

\section{ACKNOWLEDGEMENTS}

The authors would like to thank the Environmental Public Authority, especially the Water Quality Monitoring department, marine monitoring, and Marine Services sections for helping in collecting the field data, and for using the appropriate devices for measuring sea surface temperature in Kuwaiti seawater. The authors would also like to thank the Kuwait Meteorological Department at Kuwait Airport for the in-situ data from their buoys, and the USGS for the freely available Landsat 8 images.

\section{References}

Ahn, Y. H., Shanmugam, P., Lee, J. H., \& Kang, Y. Q. (2006). Application of satellite infrared data for mapping of thermal plume contamination in the coastal ecosystem of Korea. Marine Environmental Research, 61(2), 186-201. https://doi.org/10.1016/j.marenvres.2005.09.001

Al-Rashidi, T. B., El-Gamily, H. I., Amos, C. L., \& Rakha, K. A. (2009). Sea surface temperature trends in Kuwait Bay, Arabian Gulf. Natural Hazards, 50(1), 73-82. https://doi.org/10.1007/s11069-008-9320-9

Albanai, J. A. (2019). A GIS Science Simulation for the Expected Sea Level Rise Scenarios on Failka Island in The State of Kuwait ( $1^{\text {st }}$ ed.). Kuwait: Center For Research and Studies on Kuwait.

Albanai, J. A. (2020). Sea Level Rise Projections for Failaka Island in The State of Kuwait. Transaction on Maritime Science, 9(2), 236 - 247. https://doi.org/10.7225/toms.v09.n02.008.

Albanai, J. A. (2021a). Seawater Quality Atlas of the State of Kuwait (1 $1^{\text {st }}$ ed.). Kuwait: Center For Research and Studies on Kuwait.

Albanai, J. A. (2021b). Seasonal Spatial and Temporal Distribution of Chlorophyll-a Concentration over Kuwait and the Arabian Gulf using Satellite and In-Situ Data. preprints, 2021070232. https://doi.org/10.20944/preprints202107.0232.v1.

Albanai, J. A. (2021c). Mapping Kuwait bathymetry using passive multispectral remote sensing. Kuwait Journal of Science 48(4), 1-10. https://doi.org/10.48129/kjs.v48i4.8978.

Alyamani, F., Bishop, J., Ramadhan, E., Al-Husaini, M., \& Al-Ghadban, A. (2004). Oceanographic Atlas of Kuwait's waters ( $1^{\text {st }} \mathrm{ed}$.). Kuwait Institute for Scientific Research. 
Barseem, M. S., Sayed, A. N. El, \& Youssef, A. M. (2014). Impact of geologic setting on the groundwater occurrence in wadis El Sanab, Hashem, and Khrega using geoelectrical methods - northwestern coast, Egypt. Arab J Geosci 7, 5127-5139

https://doi.org/10.1007/s12517-013-1129-5

Environment Public Authority. (2020). eMISK. Retrieved April 10, 2019, from epa.org.kw

Ghanea, M., Moradi, M., Kabiri, K., \& Mehdinia, A. (2016). Investigation and validation of MODIS SST in the northern Persian Gulf. Advances in Space Research 57(1), 127-136. https://doi.org/10.1016/j.asr.2015.10.040

Kuwait Meteorological Department. (2020). Kuwait Meotrlogical Department. Retrieved February 11, 2020, from met.gov.kw

L3HARRIS. (2020). Radiometric Calibration. Retrieved April 10, 2019, from 13harrisgeospatial.com/docs/RadiometricCalibration.html

Moradi, M., \& Kabiri, K. (2015). Spatio-temporal variability of SST and Chlorophyll-a from MODIS data in the Persian Gulf. Marine Pollution Bulletin, 98(1-2), 14-25. https://doi.org/10.1016/j.marpolbul.2015.07.018

NASA. (2020). Landsat Science. Retrieved January 9, 2020, from landsat.gsfc.nasa.gov/landsat-data-continuity-mission/

PACI. (2018). Kuwait Statistics. Retrieved December 1, 2018, from paci.gov.kw/stat/

Syariz, M. A., Jaelani, L. M., Subehi, L., Pamungkas, A., Koenhardono, E. S., \& Sulisetyono, A. (2015). Retrieval of sea surface temperature over Poteran Island water of Indonesia with Landsat 8 TIRS image: A preliminary algorithm. International Archives of the Photogrammetry, Remote Sensing and Spatial Information Sciences - ISPRS Archives, 40(2W4), 87-90. https://doi.org/10.5194/isprsarchives-XL-2-W4-87-2015

Taylor, P., Seida, M. M. A., \& Sarawi, M. A. Al. (2015). Utilization and management of coastal areas in Kuwait Utilization and Management of Coastal Areas in Kuwait. 18(4) 385, 401. https://doi.org/10.1080/08920759009362122

USGS. (2020a). Earth Explorer. Retrieved January 7, 2020, from earthexplorer.usgs.gov

USGS. (2020b). Landsat 8 band designations. Retrieved March 14, 2020, from usgs.gov/media/images/landsat-8-band-designations

Wloczyk, C., Richter, R., Borg, E., \& Neubert, W. (2006). Sea and lake surface temperature retrieval from Landsat thermal data in Northern Germany. International Journal of Remote Sensing, 27(12), 2489-2502. https://doi.org/10.1080/01431160500300206

Submitted: $15-04-2020$

Revised: $\quad 08-01-2021$

Accepted: $07-02-2021$

DOI: $10.48129 /$ kjs.v49i1.9549 